\title{
Earth's Atmospheric Dynamics and Temperature and Pressure Profiles Over a Low-Latitude Indian Station Using Different Remote Sensing Techniques - A Case Study
}

\author{
M. Satyavani ${ }^{1}$, P. S. V. Subba Rao ${ }^{1}$, V. Naveen Kumar ${ }^{2}$, K. Tarakeswara Rao ${ }^{3}$, \\ P. S. Brahmanandam ${ }^{4, *}$ and M. P. Rao ${ }^{1}$ \\ 1Department of Physics, Andhra University, Visakhapatnam 500 017, India; msvanip@gmail.com, raopsvs@ \\ rediffmail.com,raomp@yahoo.com \\ 2Dept. of Basic Science, Gudlavalleru Engineering College, Gudlavalleru 521356, India; \\ vangipurapu1980@gmail.com \\ 3 Systems Design, Andhra University, Visakhapatnam 500 017, India; ktarak7777@gmail.com \\ ${ }^{4}$ Department of Basic Science, Shri Vishnu Engineering College for Women, Bhimavaram 534 202, India; \\ anand1576@gmail.com
}

\begin{abstract}
Background/objectives: Even after plenty of inclusive studies, the earth's lower atmospheric dynamics and a few important atmospheric parameters (temperature and pressure, etc.) have not yet been completely understood, particularly over equatorial and low-latitude regions. Methods/analysis: An attempt is made here by effectively utilising various ground- and satellite-based remote sensing instrument (Doppler sodar) data over a typical low-latitude Indian station, i.e. Gadanki $\left(13.45^{\circ} \mathrm{N}, 79.16^{\circ} \mathrm{E}\right)$, to understand different atmospheric dynamics, and the critical behaviors of temperature and pressure profiles as measured by radiosonde and COSMIC RO techniques are presented. Findings: Zonal, meridional and vertical winds measured using the Doppler sodar showed distinct diurnal and nocturnal variations; most importantly, the evolution of night-time boundary layer was observed. A one-to-one correspondence was seen between radiosonde measured and COSMIC RO measured temperature and pressure profiles. Applications/improvements: This study recommends that it is very much essential to use different available datasets from various remote sensing instruments to completely understand the earth's atmospheric dynamics since various dynamical interactions play a role in dictating them directly and indirectly near the earth's surface.
\end{abstract}

Keywords: Low-latitude Station, Doppler Sodar, Radiosonde, COSMIC RO Technique, Atmospheric Dynamics, Nocturnal Boundary Layer

\section{Introduction}

Knowledge of the altitudinal profile of wind information of a site is very much essential as it is useful in many aspects of wind energy development, in general, and aviation purposes, in particular. The prevailing wind and its associated parameters have long been measured using a cup anemometer arrangement, a de facto standard instrument used in the measurement of wind. Nevertheless, the installation of a cup anemometer on a mast often poses several technical problems that led to looking out for different significant and flexible wind

${ }^{*}$ Author for correspondence 
monitoring methods. $\stackrel{1}{ }$ On the other hand, LIDAR (LIght Detection And Ranging) and SODAR (SOund Detection And Ranging) are two effective remote sensing techniques that are being extensively used by the scientific fraternity to measure wind direction and speed up to a few several kilometers.

These remote sensing techniques are far superior to the conventional cup anemometers in measuring wind, because of their unique and useful characteristics which include measurement of higher-altitude (vertical) winds, highervolume measurements, ease of installation, portability and its ability to be operated for hours together unattended.

Further, it is an undeniable fact that the sole usage of the so-called remote sensing instruments cannot serve the purpose. In other words, remote sensing instruments complemented with other ground- and satellite-based instruments could only provide a complete picture of the various atmospheric dynamics and their evolutions in terms of hourly, daily, monthly, or seasonal variations. Particularly, the signs of progress in recent satellite-based instruments and their technologies have provided new perspectives in atmospheric dynamics. With the initiation of radio occultation technique (RO) on solo (GPS/MET, CHAMP, SAC-C, and GRACE) and multiple microsatellites (COSMIC), a new era has started in a complete understanding of the lower and upper atmosphere with unprecedented horizontal and vertical resolutions. $2, \underline{3}$

The present study has used various remote sensing instruments to report a few important dynamics of the earth's lower atmosphere, where the atmospheric boundary layer $(\mathrm{ABL})^{4}$ exists, including wind direction and speed and an attempt was made to evaluate the background conditions by making comparisons between two independent remote sensing techniques. The organisation of this article is as follows: Section 2 presents data and the method of analysis, and it also introduces the radio occultation technique and its advantages. In section 3 , various observational results and associated discussion are presented, and section 4 will have conclusions, followed by acknowledgments.

\section{Data and Method of Analysis}

Zonal, meridional and vertical winds were measured using the Gadanki Doppler sodar, which operates at a frequency of $1800 \mathrm{~Hz}$. Doppler sodar wind measurements were made in the altitude range of $30-1500 \mathrm{~m}$ in three directions, including east, north, and vertical. The interested readers can go through a research paper published by $\underline{5}$ regarding technical specifications, signal processing, data quality control, and preliminary validation of the Doppler sodar data. Also, nearby radiosonde and GPS-based COSMIC $\mathrm{RO}^{6}$ measured temperature and pressure profiles are also presented to verify the background atmospheric conditions during the study period. In general, one can see moderate differences in temporal and spatial variations between Gadanki location and radiosonde and COSMIC RO profiles. However, because the atmospheric parameters do not change much over a temporal range up to 0200 hours and the spatial range up to $200 \mathrm{~km}$, it may be reasonable to make a comparison between them. $\underline{7}$

COSMIC RO technique was initiated jointly by Taiwanese and US governments in 2006, and it is a constellation of six low-earth orbiting (LEO) satellites with an inclination of around $56^{\circ}$. A constellation of six micro-satellites, named COSMIC RO technique, is able to collect global lower atmosphere (bending angle, refractivity, temperature and water vapour) and ionospheric profiles (electron densities) with unprecedented vertical and horizontal resolutions from 15 April 2006 onwards. Several important atmospheric and ionospheric studies are reported using COSMIC RO measured data products. $\underline{\underline{\theta}} \underline{\underline{11}}$

\section{Observations and Discussion}

The geographical location of Gadanki (latitude $13.45^{\circ} \mathrm{N}$, longitude $79.16^{\circ} \mathrm{E}$ ) is provided in Figure 1 along with their elevations in meters. It is clear from this figure that the present location is situated in a valley region surrounded by hills with moderate heights ( 300-400 m elevation) on the west side.

Figures 2 and 3 show Doppler sodar measured variations of zonal and meridional winds on 8 January

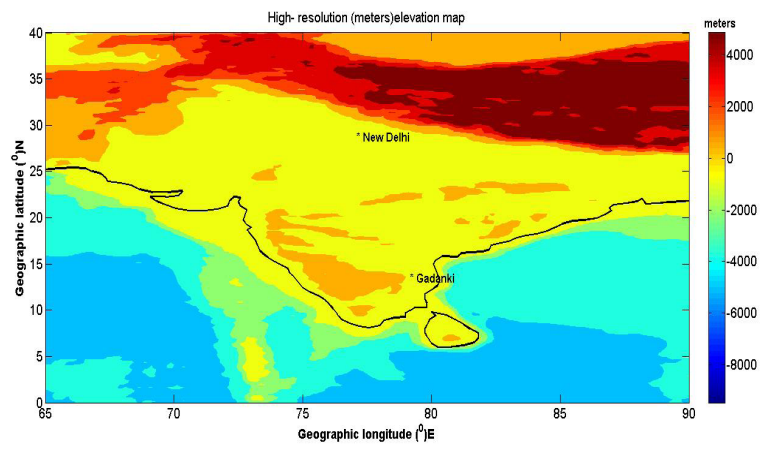

Figure 1. Topography near Gadanki and other surrounding areas as shown by a high-resolution map. 


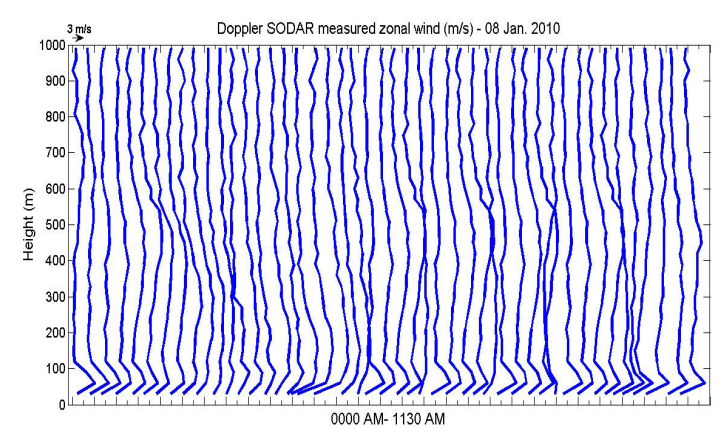

Figure 2. Stacked zonal winds $(\mathrm{m} / \mathrm{s})$ measured on 8 January 2010 .

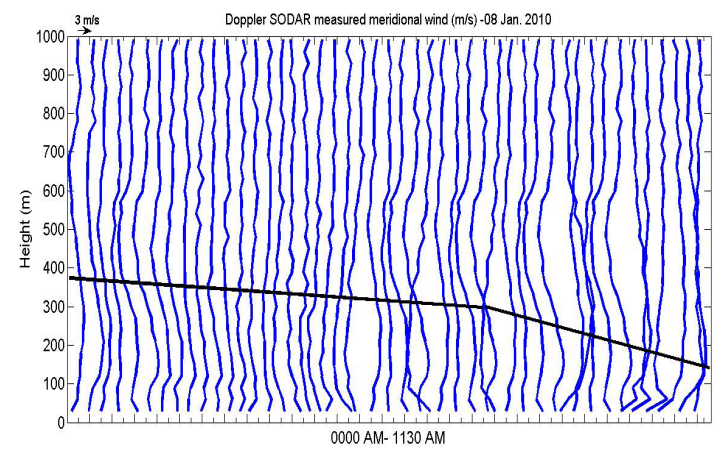

Figure 3. Stacked meridional winds $(\mathrm{m} / \mathrm{s})$ measured on 8 January 2010 from 0000 to 1130 local time.

2010 from 0000 to 1130 local time (LT= UT+0530 hrs) in a stacked manner, and these winds are 0030 minutes averaged winds. Note that the positive (negative) sign of zonal wind indicates eastward (westward) direction, while the positive (negative) sign of meridional wind indicates northward (southward) direction, and in the case of vertical wind, it indicates upward (positive sign) and downward (negative sign) directions. By looking at these stacked format winds, the evolution of the nocturnal boundary layer can be easily seen, and such observational results are presented in the ensuing lines. On the other hand, the vertical winds, as shown in Figure 4, not only show meager magnitudes, as expected, but also show upward velocities up to $500 \mathrm{~m}$, and beyond that, irregular behaviors are associated with them. Zonal and meridional winds (averaged over 15-minute intervals) measured on 8 January 2010 are depicted in Figures 5 and 6. Interestingly, though the magnitudes of them are almost equal, distinct variations in their directions can be seen. For instance, zonal winds show eastward directions from the surface of the earth to till approximately 500 meters, and

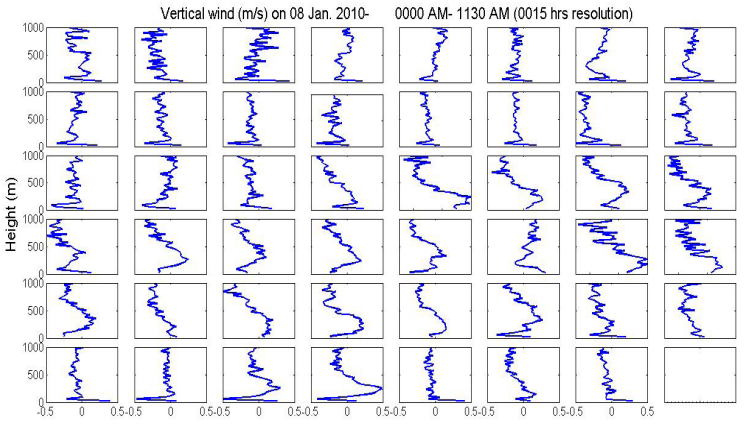

Figure 4. Temporal variations of vertical winds on 8 January 2010 from 0000 to 1130 local time.

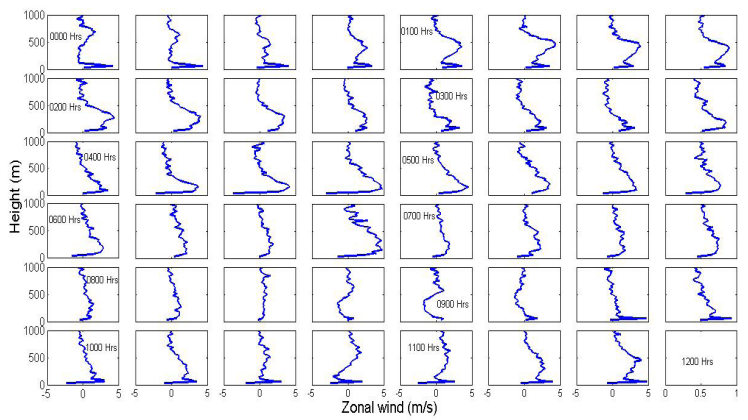

Figure 5. Temporal variations of zonal winds on 8 January 2010 from 0000 to 1130 local time.

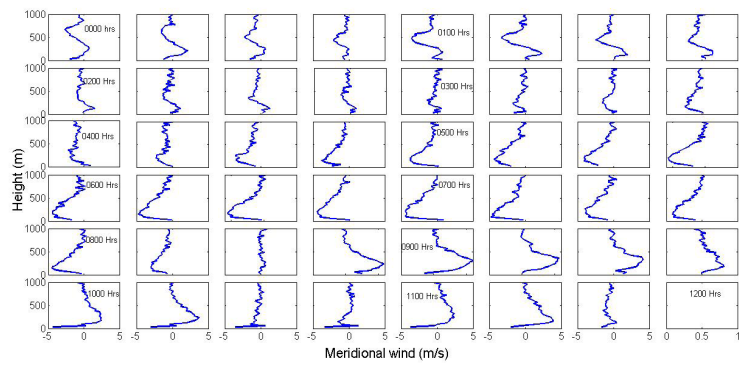

Figure 6. Temporal variations of meridional winds on 8 January 2010 from 0000 to 1130 local time.

beyond that, they show, in major of the cases, westward directions. Nevertheless, meridional winds do not follow any systematic directions that may be attributed to the sudden temperature variations, geography, and other parameters. $\underline{12}$

Zonal and meridional winds measured on 9 January 2010 are presented in Figures 7 and 8, and the evolution of $\mathrm{ABL}$ is also shown using a continuous thick line. And these stacked diagrams were used to know the 


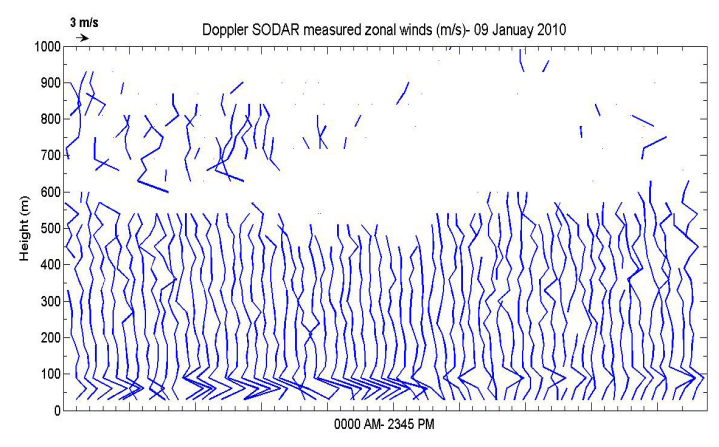

Figure 7. Stacked zonal winds $(\mathrm{m} / \mathrm{s})$ measured on 9 January 2010.

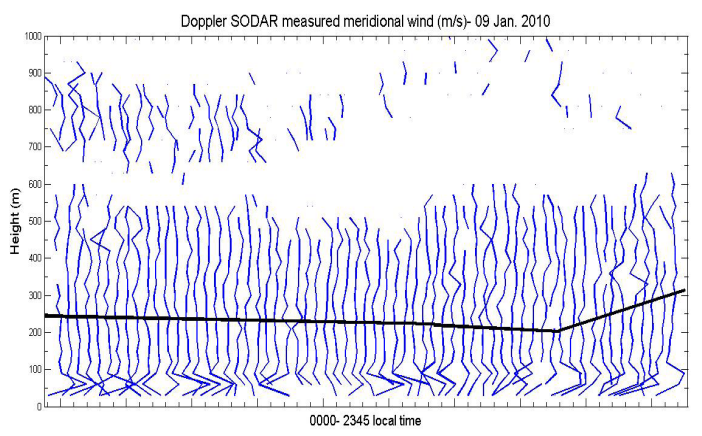

Figure 8. Stacked meridional winds $(\mathrm{m} / \mathrm{s})$ measured on 9 January 2010 and evolution of boundary layer during a day.

evolution of ABL. To know the exact wind directions and magnitudes, we present the temporal variations of zonal, meridional, and vertical winds in Figures 9, 10, and 11. It may be observed from Figures 9, 10 and 11 that vertical winds show irregular directions, while zonal winds

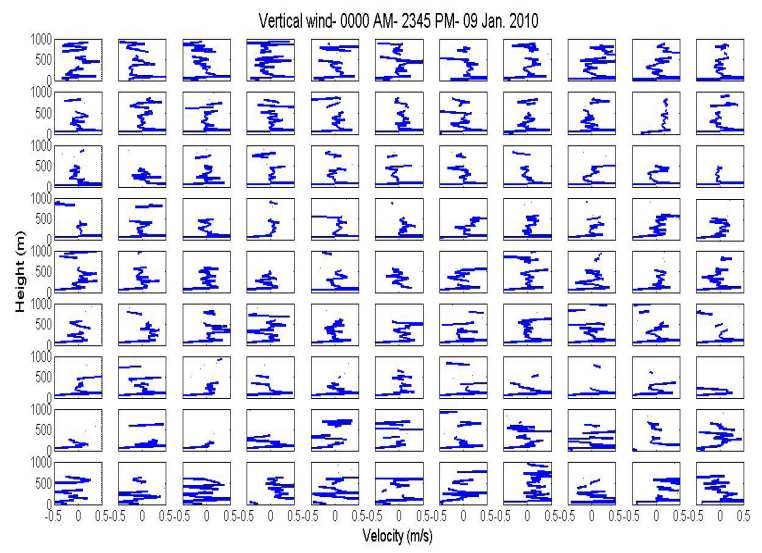

Figure 9. Temporal variations of vertical winds on 9 January 2010 from 0000 to 2345 local time.

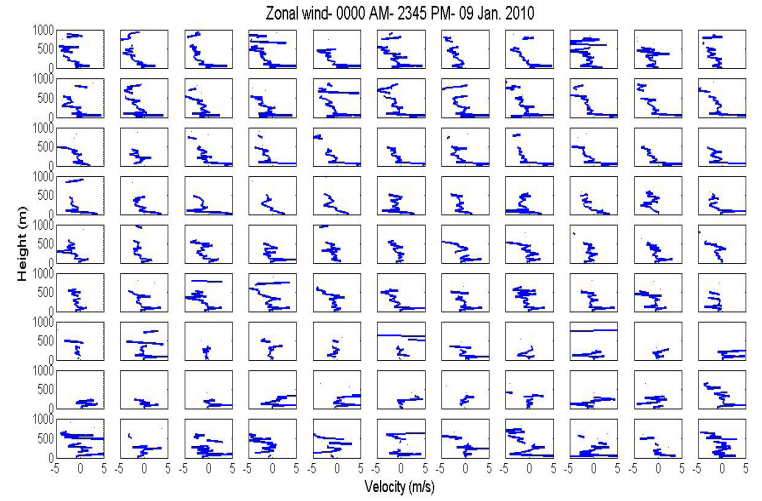

Figure 10. Temporal variations of zonal winds on 9 January 2010 from 0000 to 2345 local time.

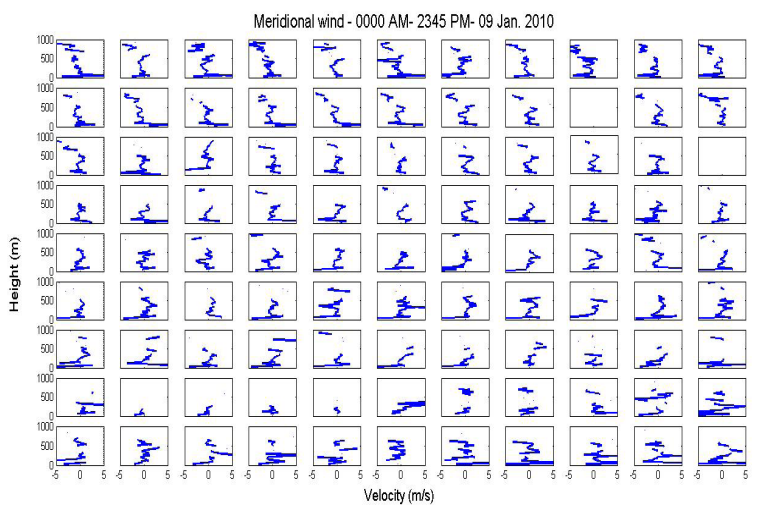

Figure 11. Temporal variations of meridional winds on 9 January 2010 from 0000 to 2345 local time.

show eastward direction till $\sim 500 \mathrm{~m}$, and later on show the westward direction in the majority of cases. On the other hand, meridional winds show northward directions till $\sim 400-500 \mathrm{~m}$, and beyond that, they show southward directions in the majority of cases.

To properly present and understand the directions and magnitudes of the winds, we present them using wind rose diagrams. Figures 12 and 13 show wind rose diagrams of winds measured on 8 and 9 January 2010, respectively. It is clear that the magnitudes of winds on 8 January 2010 were found to be between 0 and $10 \mathrm{~m} / \mathrm{s}$ ( $\sim 0-36 \mathrm{~km} / \mathrm{h}$ or $\sim 0-22.36 \mathrm{miles} /$ hour) only, which comes under "fresh breeze" category, according to the Beaufort scale (1805). However, wind directions and magnitudes on 9 January 2010 were completely different as shown in Figure 13. A close look at wind rose diagram reveals that wind speeds were found to be between 0 and 15 $\mathrm{m} / \mathrm{s}(\sim 0-54 \mathrm{~km} / \mathrm{h}$ or $\sim 0-33.6$ miles/hour), which comes under "strong breeze" category, according to the Beaufort 


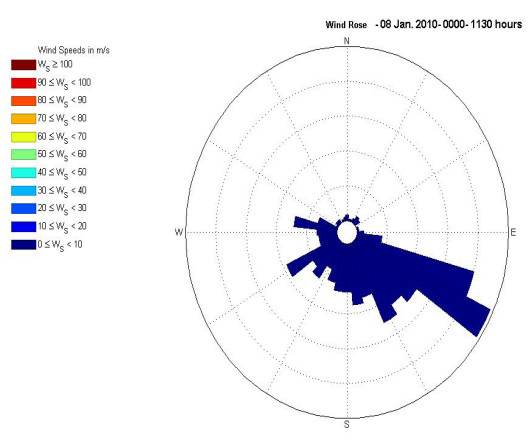

Figure 12. Wind rose diagram for winds observed on 8 January 2010 between 0000 and 1130 local time.

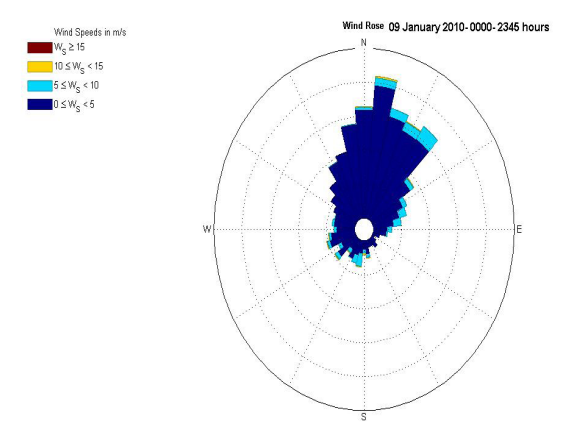

Figure 13. Wind rose diagram for winds observed on 9 January 2010 between 0000 and 2345 local time.

scale (1805). Secondly, the directions of winds are quite different from the winds observed on 8 January 2010. The prevailing winds, on the other hand, on 9 January 2010 showed north-east directions in the majority of events.

\subsection{Evolution of Nocturnal ABL}

$\mathrm{ABL}$ is regarded as one of the important physical characteristics of land-atmosphere communication. It is known that the creation and growth of ABL are linked to surface fluxes such as net radiation and sensible heat. $\frac{13}{}$ In general, the evolution of nocturnal $\mathrm{ABL}$ can also be witnessed that is shown using a line that connects different individual maximum points. The identification of boundary is done through maximum criteria methods which include gradient, double gradient, logarithmic gradient, variational, and wavelet-based transform methods. $\underline{14}$ Figures $2-3$ and $7-8$ show the evolution of nocturnal ABL. It is evident from these figures that a gradual rise in the height of NBL with the progress of time may be observed, followed by a gradual decrease on 8 and 9 January 2010.

\subsection{Comparative Studies: Radiosonde and COSMIC RO Measured Profiles}

Radiosonde (balloon-borne instrument) is one of the oldest and highly reliable instruments used to measure temperature, pressure profiles and other important atmospheric parameters, albeit the ascent of the radiosonde is restricted to only two temporal windows ( $\sim 600$ and $\sim 1800$ local times). A drastic change of wind directions and magnitudes observed on 8 and 9 January 2010 is quite interesting, and a few clues regarding that may be revealed if an attempt is made to evaluate the background conditions. By keeping that view in mind, we present temperature and pressure profiles as measured by radiosonde and COSMIC RO technique. The COSMIC satellite projections near Gadanki are shown in Figures 14 and 15. It is important to mention here that there will be two types of occultation paths which include "rising"

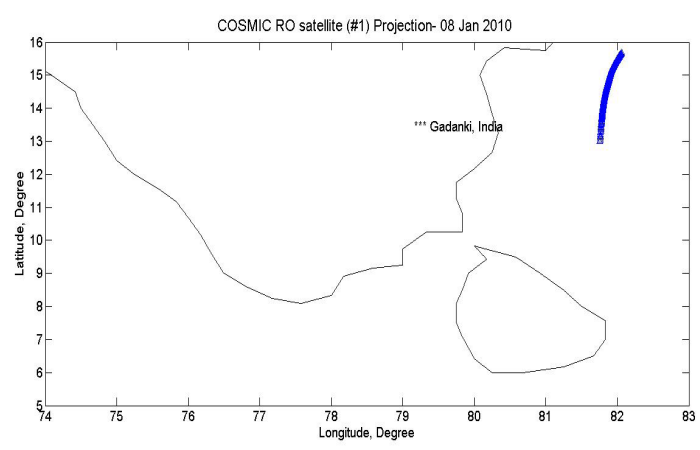

Figure 14. COSMIC RO microsatellite (\#1) projection near Gadanki on 8 January 2010.

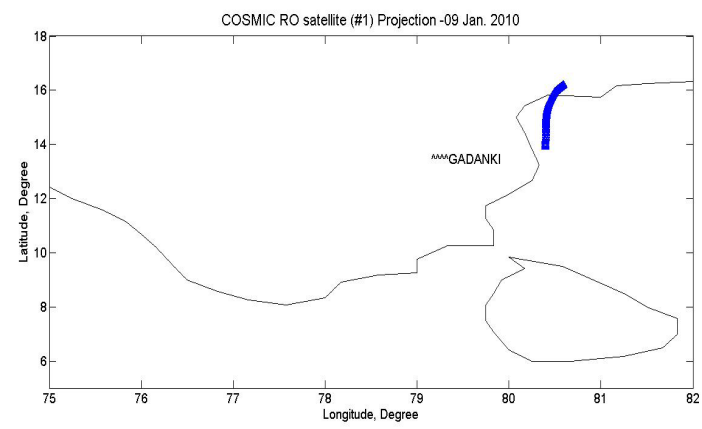

Figure 15. COSMIC RO microsatellite (\#1) projection near Gadanki on 9 January 2010. 
and "setting" occultations, based on the geometry of GPS satellite and COSMIC micro-satellites. $\frac{15}{}$

The temperature and pressure profiles measured on 8 and 9 January 2010 by radiosonde and COSMIC RO technique are presented in Figures 16-19, respectively. Often, it is quite interesting to note from these figures that the altitude of (radiosonde) balloon does not reach the expected $30 \mathrm{~km}$ range, primarily because of the burst of the balloon when it ascends to such altitudes where the pressure level is too meager. On the other hand, temperature and pressure profiles at such altitudes can be easily probed by COSMIC micro-satellites. It is quite obvious from these figures that the trends of temperature and pressure profiles are almost the same during these days, in the similar lines with earlier studies. $\frac{16}{16}$ Nevertheless, a slight difference in the tropopause height, as probed by these two independent observations, could be witnessed that may be attributed to these two independent observations and their way of functioning in probing atmospheric parameters. Tropopause heights (in
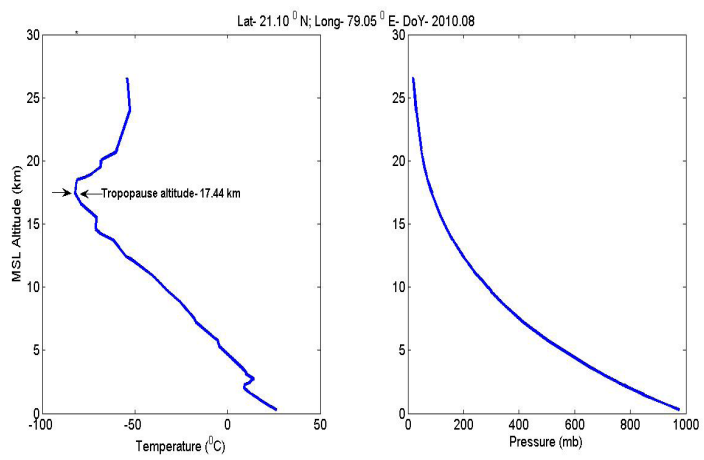

Figure 16. Radiosonde measured temperature and pressure profiles on 8 January 2010 near Gadanki.
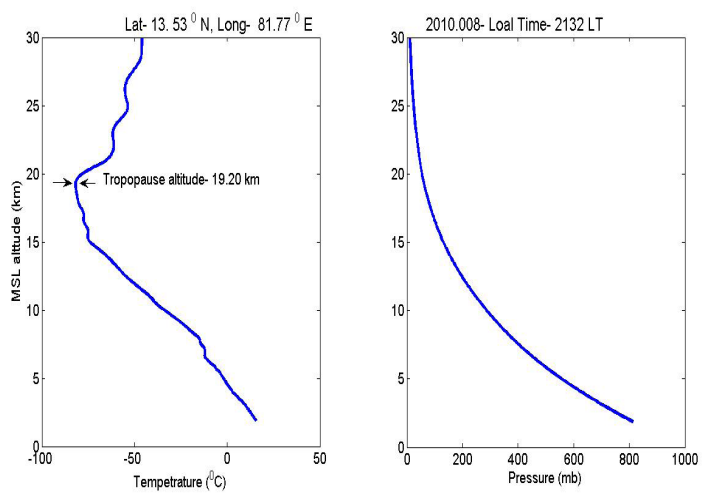

Figure 17. COSMIC RO measured temperature and pressure profiles on 8 January 2010 near Gadanki.

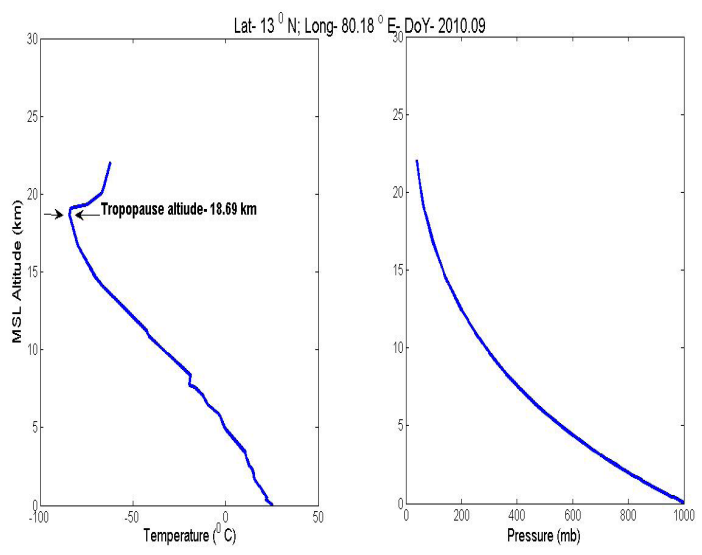

Figure 18. Radiosonde measured temperature and pressure profiles on 9 January 2010 near Gadanki.

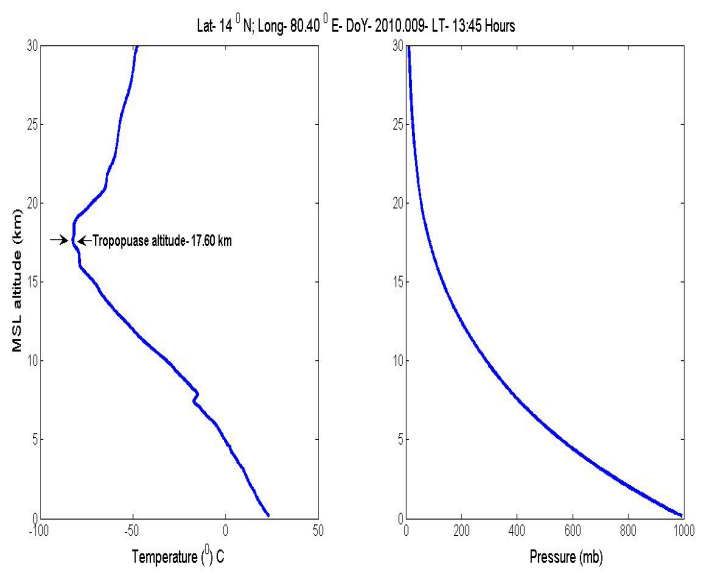

Figure 19. COSMIC RO measured temperature and pressure profiles on 9 January 2010 near Gadanki.

$\mathrm{km}$ ) as measured by the two independent techniques on 8 and 9 January 2010 are provided in Table 1.

\section{Conclusion}

The following important observations were noticed as far as this present research is concerned.

i. Distinct variations of zonal, meridional, and vertical winds (in terms of their directions and magnitudes) were noticed.

ii. Zonal winds initially propagated to the eastward directions from the earth's surface to approximately $500 \mathrm{~m}$ in the majority of the cases, while they tended to propagate towards westward direction beyond that altitude. 
Table 1. Tropopause heights measured using radiosonde and COSMIC RO technique on 8 and 9 January 2010

\begin{tabular}{|l|l|l|l|l|}
\hline \multirow{2}{*}{ S. no. } & \multicolumn{2}{|l|}{$\mathbf{8}$ January 2010 } & 9 January 2010 \\
\cline { 2 - 5 } & $\begin{array}{l}\text { Tropopause height } \\
(\mathbf{k m})\end{array}$ & $\begin{array}{l}\text { Geographic latitude } \\
\text { and longitude }\end{array}$ & $\begin{array}{l}\text { Tropopause height } \\
(\mathbf{k m})\end{array}$ & $\begin{array}{l}\text { Geographic latitude and } \\
\text { longitude }\end{array}$ \\
\hline Radiosonde & 17.44 & $21.16^{\circ} \mathrm{N} \& 79.05^{\circ} \mathrm{E}$ & 19.20 & $13^{\circ} \mathrm{N} \& 80.18^{\circ} \mathrm{E}$ \\
\hline COSMIC RO technique & 18.69 & $13.53^{\circ} \mathrm{N} \& 81.77^{\circ} \mathrm{E}$ & 17.69 & $14^{\circ} \mathrm{N} \& 80.40^{\circ} \mathrm{E}$ \\
\hline
\end{tabular}

iii. No consistent directions were found for meridional winds, meaning they often showed northward directions and sometimes southward directions.

iv. However, the wind rose diagrams showed relatively a clear picture of the direction and magnitude of winds.

v. The evolution of nocturnal ABL was clearly noticed, which shows a gradual increase till early morning hours, and later, it descends to lower altitudes with the progress of time.

vi. The comparison of temperature and pressure profiles of two independent observational techniques (radiosonde and occultation) showed that one-to-one correspondence was noticed between them.

vii. A near similitude between tropopause heights as measured by radiosonde and occultation technique was observed.

viii. An effective utilisation of several remote sensing techniques always would fetch benefits in earth's atmospheric studies, since it is highly dictated by several complex phenomena and interactions.

\section{Acknowledgements}

The authors would like to express their sincere thanks to the scientists, technical and non-technical staff of NARL, Gadanki, AP, India, for providing valuable Doppler sodar, without which this present work would not have been possible. The authors further wish to thank CDAAC, Boulder, USA, for keeping radio occultation data on their website, which we utilised in this study.

\section{References}

1. Lang S, McKeogh E. LIDAR and SODAR measurements of wind speed and direction in upland terrain for wind energy purposes. Remote Sens.2011;3:1871-901.
2. Brahmanandam PS, Chu YH, Liu J. Observations of equatorial Kelvin wave modes in FORMOSAT-3/COSMIC GPS RO temperature profiles. Terr Atmos Ocean Sci (TAO). 2010;21:829-40.

3. Anthes RA. Exploring earth's atmosphere with radio occultation contributions to weather, climate and space weather. Atmos Meas Tech. 2011;4:1077-103.

4. An introduction to boundary layer meteorology. [cited 1988]. https://www.springer.com/gp/book/9789027727688.

5. Anandan VK, Shravan Kumar M, Srinivasa Rao I. First results of experimental tests of newly developed NARL phased array Doppler sodar. J Atmos Ocean Technol. 2008;25:1778-84.

6. Cheng CZF, Kuo YH, Anthes RA, Wu L. Satellite constellation monitors global and space weather. Eos Trans Am Geophys Union. 2006;87(17):166.

7. Anisetty PR, Brahmanandam PS, Uma G. Planetary-scale wave structures of the earth's atmosphere revealed from the COSMIC observations. J Meteorol Res. 2014;28:281-95.

8. Brahmanandam PS, Chu YH, Wu KH. Vertical and longitudinal electron density structures of equatorial $\mathrm{E}$ and F-regions. Ann Geophys. 2012;29:81-9.

9. Uma G, Brahmanandam PS, Chu YH. A long-term study on the deletion criterion of questionable electron density profiles caused by ionospheric irregularities COSMIC radio occultation technique. Adv Space Res. 2016;57(12):2452-63.

10. Uma G, Brahmanandam PS, Tulasi Ram S, Wu KH, Chu YH. A complete solar cycle (2006-2016) studies of scale heights derived using COSMIC radio occultation retrieved electron density profiles. J Atmos Sol-Terr Phys. 2019;182:101-18.

11. Uma G, Brahmanandam PS, Srinivasu VKD, Prasad DSVVD, Sai Gowtam V, Tulasi Ram S, et al. Ionospheric responses to the 21 August 2017 great American solar eclipse - a multi-instrument study. Adv Space Res. 2019:112. https://doi.org/10.1016/j.asr.2019.09.010

12. Katsaprakakis DA, Christakis DG. Wind parks design, including representative case studies. In: Comprehensive renewable energy. 2012. P. 169-223. 
13. Brahmanandam PS, Kumar VN, Kumar GA. A few important features of global atmospheric boundary layer heights estimated using COSMIC radio occultation retrieved data. Indian J Phys. 2019:1-9. https://doi. org/10.1007/s12648-019-01514-7

14. Naveen Kumar V, Brahmanandam PS, Purnachandra Rao M, Anil Kumar G, Samatha K, Rupa Dhanasri L. A study of atmospheric boundary layer (ABL) height estimation using various analytical methods - COSMIC RO measured temperature profiles. Indian J Sci Technol. 2018;11(31):1-12.
15. Yue X, Schreiner WS, Pedatella N, Anthes RA, Mannucci AJ, Straus PR, et al. Space weather observations by GNSS radio occultation: from FORMOSAT-3/ COSMIC to FORMOSAT-7/COSMIC-2. Space Weather. 2014;12:616-21.

16. Mastaan R, Brahmanandam PS, Uma G, Babu AN, Reddy KK. Studies of two important stability indices of Earth's atmosphere determined by using the COSMIC GPS radio occultation technique. Indian J Sci Technol. 2016;9(38):1-9. 